\title{
The Dufourmentel modification of the limberg flap: Does it fit all?
}

\author{
Maciej Sebastian ${ }^{A-F}$, Maciej Sroczyński ${ }^{A-F}$, Jerzy Rudnicki ${ }^{A-F}$ \\ Department of Minimally Invasive Surgery and Proctology, Wroclaw Medical University, Poland \\ A - research concept and design; B - collection and/or assembly of data; $C$ - data analysis and interpretation; \\ $D$ - writing the article; $E$ - critical revision of the article; $F$ - final approval of article
}

\section{Address for correspondence \\ Maciej Sebastian \\ E-mail:mseba@op.pl \\ Funding sources \\ none declared}

\section{Conflict of interest}

none declared

Received on March 7, 2015

Revised on April 30, 2015

Accepted on June 10, 2015

\begin{abstract}
Background. Pilonidal disease is a common problem, especially in young adults. Therapy for the acute disease involves abscess incision and drainage. Treatment of the chronic disease is more complicated, due to the variety of methods and relatively high recurrence rate after surgical therapy.

Objectives. The aim of this study was to investigate the effects of the Dufourmentel modification of the Limberg flap in the treatment of pilonidal disease.

Material and methods. The study involved 37 cases of chronic pilonidal disease that were operated on by the method presented. The group included 34 patients with primary disease and three patients with recurrences after primary excision.

Results. The complication rate in the study group was $8.1 \%$, but the complications were successfully treated, surgically in one patient (using the same method) and non-surgically in two other patients. There were also two cases of temporary numbness in the operated area. The only disadvantage of the method presented may be the cosmetic results, but they were not the most important factor for the patients in the study.

Conclusions. The authors find the Dufourmentel modification of the Limberg flap superior to other methods of treating pilonidal disease due to its flexibility, simplicity of reconstruction, repeatability and good outcomes in terms of the recurrence rate. These factors are extremely important to young and active patients who are diagnosed with pilonidal disease.
\end{abstract}

Key words: recurrence, pilonidal disease, rhomboid flap

DOI

10.17219/acem/44483

\section{Copyright}

Copyright by Author(s)

This is an article distributed under the terms of the

Creative Commons Attribution Non-Commercial License

(http://creativecommons.org/licenses/by-nc-nd/4.0/) 
Pilonidal disease (PD) is a common disease of young adults that occurs 2 times as frequently in men as in women, with an incidence of nearly $25 / 100.000 .^{1}$ A hirsute body habitus, a deep gluteal cleft, obesity, smoking, a sedentary lifestyle, a lack of hygiene and previous familial history have been suggested as predisposing factors. ${ }^{2}$ According to the two principal theories, the disease can be either "congenital" (the infection arising from a congenital subcutaneous pilonidal sinus) or "acquired" (resulting from traction on the pilous follicles in the gluteal cleft, especially when predisposing factors are present). Hair strands grow beneath the skin, leading to local inflammation, the foreign body reaction and infection. ${ }^{3}$

Treatment for acute PD consists of abscess incision and drainage. The chronic form can be managed in many ways, from removal of all the infected tissue or only unroofing the pilonidal sinuses, leaving the wound open to heal by secondary intention before using plastic surgery techniques such as a Karydakis flap (KF) or Limberg flap (LF). ${ }^{3}$ The authors of a meta-analysis of 25 trials (2,949 patients) suggested that open radical excision and primary midline closure should be abandoned in favor of sinusotomy/sinectomy or en bloc resection with off-midline primary closure. ${ }^{4}$ The authors of the present article performed radical excision with primary midline closure before the introduction of the Dufourmentel modification of the Limberg flap (DMLF), but the outcomes were poor, especially in patients with PD and laterally localized sinuses. This forced us to look for another method. The problem was the closure of the wound under tension, which ended in early failure, suture-line breakdown and healing by secondary intention. Flap coverage of the defect leads to shorter healing times and better results in terms of postoperative pain, the recurrence rate and the patient's return to everyday activities. ${ }^{5}$ The DMLF is a way to broaden the application of the rhombic flap.

\section{Material and methods}

During the period from March 2013 to November 2014, DMLFs were performed in 37 patients with PD at the authors' center; among them were 3 patients with recurrent PD after simple excision in other medical centers. During this time all the patients with PD who were operated on by the authors were qualified for DMLFs. The exclusion criteria for DMLFs were active inflammation in the operated area, which qualified patients only for unroofing and drainage. Patients with chronic PD were qualified for DMLFs, especially when the sinuses wen localized laterally (off the midline). The patients included 35 men and 2 women, with a median age of 24 years (range $=17-36$ years) (Table 1).

Before the incision, methylene blue was injected into the opening of each sinus and the lines of incision were
Table 1. Principal characteristics of the study group

\begin{tabular}{|lc|}
\hline Men/Women & $35 / 2$ \\
\hline Mean age (years) & $24(17-36)$ \\
Wound complications: & $5(4-6)$ \\
- wound dehiscence (\%) & \\
- necrosis of the flap (\%) & 0 \\
- temporary discharge (\%) & 0 \\
- recurrence (\%) & $5.4(2)$ \\
- temporary numbness (\%) & $2.7(1)$ \\
- dissatisfaction with the cosmetic results (\%) & $5.4(2)$ \\
\hline
\end{tabular}

drawn with a sterile surgical pen and ruler. The flap was formed as described by Park and Little: "To design the flap, two lines are created. The first line is an extension of the short diagonal of the defect, and the second is an extension of one side of the defect. The angle created by these two lines is bisected by a third line to create the first side of the flap, which is equal in length to the sides of the defect. The second side of the flap is drawn parallel to the long diagonal of the defect and is also of equal length to the defect's sides"6 (Fig. 1). During the procedure it is of the utmost importance to remove all the infected tissue, leaving healthy margins around the

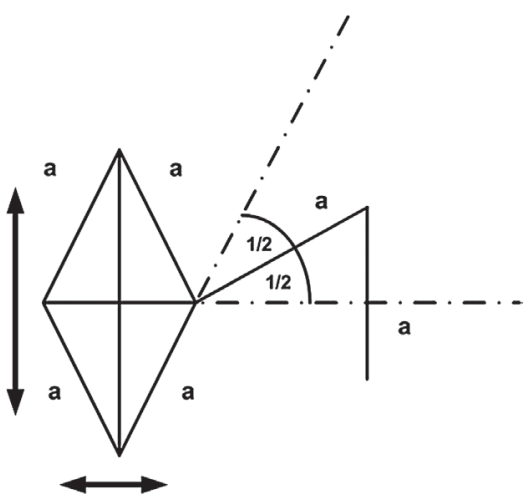

Fig. 1. The Dufourmentel modification of the Limberg flap: A schematic diagram of the lines of incision. The rhombic excision has to be adjusted to the exact extent of pilonidal disease; the resection area is very flexible

sinus (dye is very helpful for this) and to achieve effective hemostasis with electro-cauterization (Fig. 2). Resorbable 3-0 polyglactin sutures were used for closure of the subcutaneous tissue and non-resorbable interrupted 3-0 sutures were used for skin closure. Redon's suction drainage from a separate incision was left in the wound bed. The median hospital stay was 5 days (range: 4-6 days). The drain was removed after the volume of drainage was $<20 \mathrm{~mL}$, usually on the third postoperative day. The patients were given $1 \mathrm{~g}$ of second-generation cephalosporin preoperatively, and amoxicillin-clavulanic acid therapy was continued for 5 days. The stitches were removed after 12-14 days (Fig. 3). 


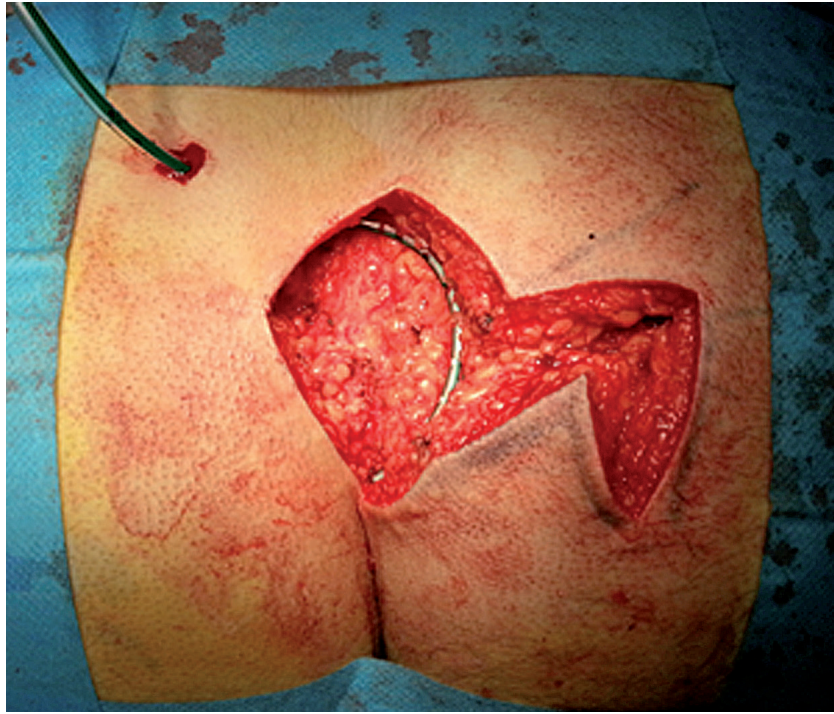

Fig. 2. Radical excision of the infected tissue en bloc is the most important part of the procedure

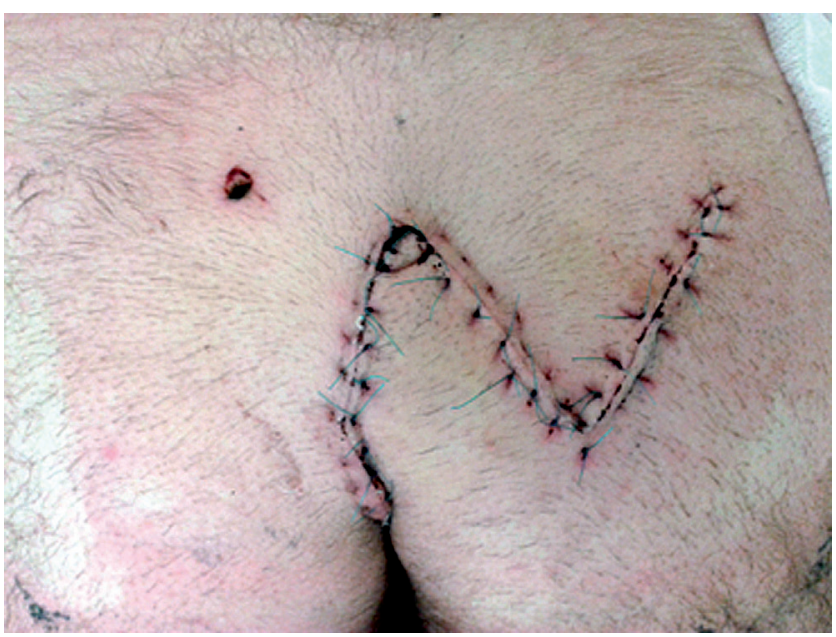

Fig. 3. Healing by primary intention on the $12^{\text {th }}$ postoperative day

\section{Results}

Temporary discharge from the wound was observed in 2 patients (5.4\%). The discharge was observed in 1 patient who did not pay attention to the hygiene of the operated area; it appeared 10 days postoperatively and lasted for 14 days. The other patient with discharge had type 2 diabetes and was being operated on for a recurrence of PD; the discharge appeared 30 days postoperatively and lasted for 21 days. In these 2 patients conservative therapy in the form of local wound hygiene and irrigation with hypertonic saline was all that was needed.

A recurrence of PD was observed in 1 patient (2.7\%) 61 days postoperatively. This was the first patient the authors had treated with a DMLF and the only patient in the study group who needed a reoperation (the learning curve no doubt came into play). The second operation gave the patient a wider DMLF, which proved successful.
There were also two cases of temporary numbness in the operated area (5.4\%). No wound dehiscence or necrosis of the flap was observed. In other patients the postoperative course was uneventful. The patients were monitored on postoperative day 12-14, when the stitches were removed and the patients were advised to contact the department if any problems occurred (the department is open $24 \mathrm{~h}$ a day, 7 days a week, and patients can contact doctors whenever any postoperative complications occur, which the authors consider better than strictly defined consultation hours).

\section{Discussion}

The DMLF permits the repair of rhombus-shaped defects with any combination of internal angles, in contrast to the Limberg flap, with angles limited to $60^{\circ}$ and $120^{\circ}$. The DMLF is a very flexible and patient-tailored treatment, and defects that are more "square" are excised with less normal tissue sacrificed. It has the advantage of a smaller area of pivot, thus creating a smaller standing cutaneous deformity. ${ }^{6}$ For the surgeon performing the operation for $\mathrm{PD}$, the most important elements contributing to a successful outcome are: 1) the removal of all sinuses, pits and potentially infectious areas; 2 ) covering the defect with healthy and well vascularized tissue in a tension-free manner; and 3) prevention of recurrence. All of these goals can be well accomplished by the DMLF. The only disadvantages of this method are the cosmetic results, which may not be very appealing. But considering the location of the disease, wound healing by primary intention and an early return to full activity, in the authors' opinion cosmetic factors are not the most important issue, and the advantages should outweigh an unfavorable cosmetic outcome. ${ }^{7}$ In a study by Altintoprak et al., the rate of dissatisfaction with the cosmetic results of the DMLF was $12.6 \%{ }^{8}$ In the present study group two patients (5.4\%) were dissatisfied with the cosmetic results of the operation, but the most important factor for all the patients was healing by first intention and a quick return to normal activity (probably especially because the patients were young).

Due to its chronic course, discharge and abscess formation, PD may lead to depression, anxiety, low self-esteem and absences from school and work. ${ }^{9}$ During treatment it is important to think about the active population that is most affected by PD, and to tailor the treatment method to the individual patient. ${ }^{4}$ In the authors' opinion, the only limitation of the DMLF is in PD that is very long (for example when the sinuses are located very low, close to the anus, or the abscess hole is high in the midline on the back), in which case another surgical method, such as KF or tandem rhomboid flaps, would be preferable. ${ }^{10}$ In this clinical situation, the DMLF would result in a very large wound with unnecessary removal of large areas of healthy 
tissue, more probable postoperative complications and poor cosmetic results.

In other situations, especially when the abscess holes and infected tissue are located laterally to the midline, the DMLF should be the preferred method (Fig. 4). Milone et al. evaluated 1006 patients with PD in whom complete excision and midline closure was achieved. They found that a previous history of PD surgery and an increased distance $(>2 \mathrm{~cm})$ of the lateral orifices from the midline were independent predictors of postoperative complications (infection and/or recurrence). They suggested offmidline surgery in these situations. ${ }^{11}$

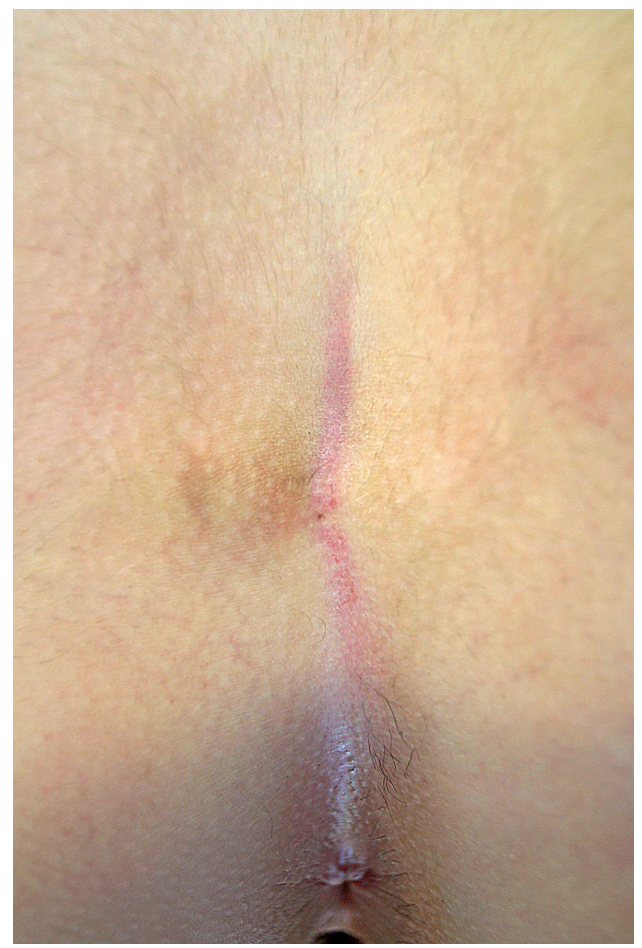

Fig. 4. A laterally located abscess hole is a classic indication for the Dufourmentel modification of the Limberg flap

Alptekin et al. found that the volume of the excised specimen in PD procedures correlates with surgical site infection. Due to the wide en bloc excision in the DMLF, it is advisable to use an empiric broad-spectrum antibiotic (extended post-discharge) as a preventive measure. ${ }^{12}$ There is a lack of strong data that would support the routine use of drainage in all patients; the decision should be based on patient-, surgery- and disease-related factors. ${ }^{13}$

Some authors find the removal of the infected tissue the easiest part of the procedure, but in the present authors' view it is the most important and the most difficult part, because if it is not performed meticulously and carefully, it can be the cause of recurrence. ${ }^{4}$ Usually the lowest part of the PD area is located on the midline and this region has to be very carefully excised, so any methods that shift the rhombic excision to the side may be end up leaving some infected tissue behind, leading to

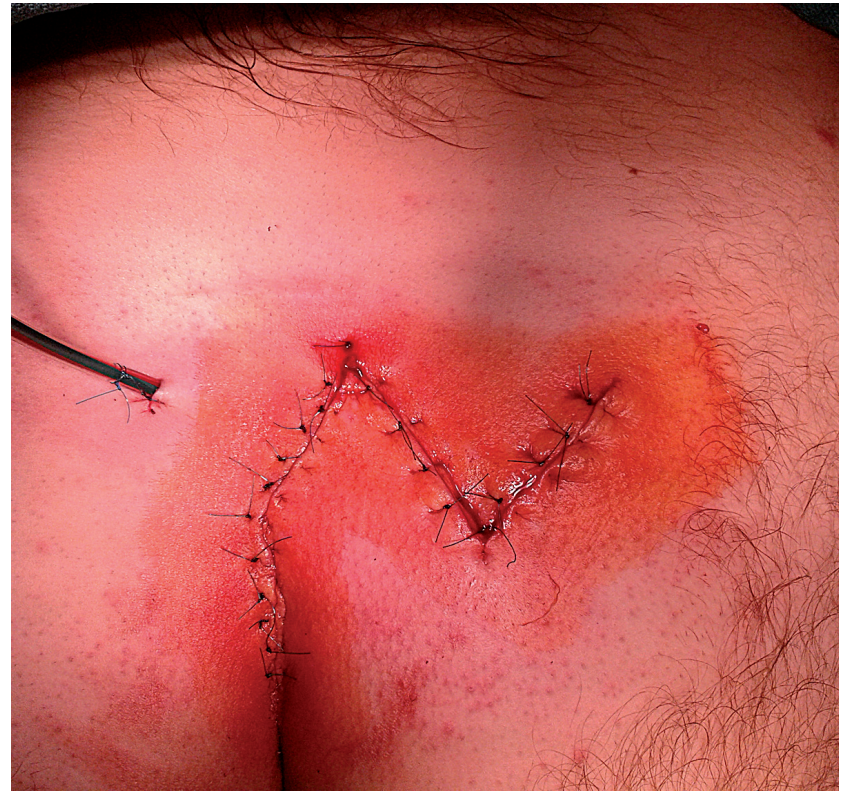

Fig. 5. Tension-free closure of the defect

a recurrence. ${ }^{2,14}$ Reconstruction is not very difficult and enables tension-free closure of the defect with flattening of the natal cleft ${ }^{2}$ (Fig. 5). One modification of this method may be a symmetrically rotated rhomboid excision, especially when the inflamed tissue is located laterally to the midline. ${ }^{14}$

In a review of 10,000 patients and 74 studies, Petersen et al. found that off-midline closure are superior to midline closure in terms of suture line breakdown and dehiscence (3-5 vs. 9\%) and recurrence (1-3 vs. 9.5\%). Better results were observed in the Limberg and Dufourmentel group in comparison to the midline-closure group (which the authors of the current study used before the introduction of the DMLF). Infection was observed in $2.6 \%$ of the Limberg and Dufourmentel group vs. $12.4 \%$ of the midline-closure group; the early failure rate was in 3.4 vs. $8.9 \%$, respectively; and the recurrence rate was 1.5 vs. 9.4\% respectively. These differences were statistically significant $\mathrm{p}<0.001 .{ }^{15}$

Lieto et al. performed DMLFs in 310 patients, among whom 55 had recurrent sinuses. All the operations were uneventful; no flap necrosis occurred, wound complications were experienced by 33 patients (10.6\%), and recurrence was observed in 7 patients $(2.3 \%)$. The authors recommend the DMLF as a method with excellent results in first- and second-line management of pilonidal disease. ${ }^{16}$

The authors recommend the DMLF as the most appropriate method in the treatment of PD due to its flexibility, repeatability, clear and predictable closure of the defect and low recurrence rate. It is highly satisfying to see young patients returning to their normal work and sport activities, and that should be the main goal of PD treatment. 


\section{References}

1. Shabbir J, Chaudhary BN, Britton DC. Management of sacrococcygeal pilonidal sinus disease: A snapshot of current practice. Int J Colorectal Dis. 2011;26:1619-1620.

2. Yoldas T, Karaca C, Unalp O, et al. Recurrent pilonidal sinus: Lay open or flap closure, does it differ? Int Surg. 2013;98:319-323.

3. De Parades V, Bouchard D, Janier M, Berger A. Pilonidal sinus disease. J Visc Surg. 2013;150:237-247.

4. Enriquez-Navascues JM, Emparanza Jl, Alkorta M, Placer C. Metaanalysis of randomized controlled trials comparing different techniques with primary closure for chronic pilonidal sinus. Tech Coloproctol. 2014;18:863-872.

5. Khan PS, Hayat $H$, Hayat G. Limberg flap versus primary closure in the treatment of primary sacrococcygeal pilonidal disease: A randomized clinical trial. Indian J Surg. 2013;75:192-194.

6. Park SS, Little S. Rhombic Flaps. In: Baker SR, ed. Local Flaps in Facial Reconstruction. Philadelphia: Elsevier Saunders.;2014:210-230.

7. El-Khadrawy O, Hashish M, Ismail K, Shalaby H. Outcome of the rhomboid flap for recurrent pilonidal disease. World J Surg. 2009; 33:1064-1068.

8. Altintoprak F, Gundogdu K, Ergonenc T, Dikicier E, Cakmak G, Celebi F. Retrospective review of pilonidal sinus patients with early discharge after Limberg flap procedure. Int Surg. 2014;99:28-34.

9. Duman K, Ozdemir Y, Yucel E, Akin ML. Comparison of depression, anxiety and long-term quality of health in patients with a history of either primary closure or Limberg flap reconstruction for pilonidal sinus. Clinics (Sao Paulo). 2014;69,:384-387.
10. Naveen N, Kumar MK, Babu KR, Dhanraj P. Tandem rhomboid flap repair: $A$ new technique in treatment of extensive pilonidal disease of the natal cleft. J Clin Diagn Res. 2014;8,:3-4.

11. Milone M, Di Minno MN, Bianco P, Coretti G, Musella M, Milone F. Pilonidal sinus surgery: Could we predict postoperative complications? Int Wound J. 2014. doi: 10.1111/iwj.12310.

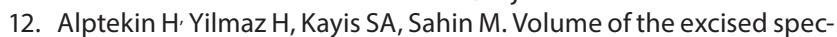
imen and prediction of surgical site infection in pilonidal sinus procedures (surgical site infection after pilonidal sinus surgery). Surg Today. 2013;43:1365-1370.

13. Milone $M$, Di Minno MN, Musella M, Maietta $P$, et al. The role of drainage after excision and primary closure of pilonidal sinus: A meta-analysis. Tech Coloproctol. 2013;17:625-630.

14. Afşarlar CE, Yılmaz E, Karaman A, et al. Treatment of adolescent pilonidal disease with a new modification to the Limberg flap: Symmetrically rotated rhomboid excision and lateralization of the Limberg flap technique. J Pediatr Surg. 2013;48:1744-1749.

15. Petersen S, Koch R, Stelzner S, Wendlandt TP, Ludwig K. Primary closure techniques in chronic pilonidal sinus: A survey of the results of different surgical approaches. Dis Colon Rectum. 2002;45:1458-1467.

16. Lieto E, Castellano P, Pinto M, Zamboli A, Pignatelli C, Galizia G. Dufourmentel rhomboid flap in the radical treatment of primary and recurrent sacrococcygeal pilonidal disease. Dis Colon Rectum. 2010;53:1061-1068. 